\title{
A kinetic model for ethylene oligomerization using zirconium/ aluminum- and nickel/zinc-based catalyst systems in a batch reactor
}

\author{
Adil A. Mohammed • Seif-Eddeen K. Fateen • \\ Tamer S. Ahmed • Tarek M. Moustafa
}

Received: 18 October 2013/ Accepted: 29 January 2014/Published online: 25 February 2014

(c) The Author(s) 2014. This article is published with open access at Springerlink.com

\begin{abstract}
The aim of this work is to develop a kinetic model of the oligomerization of ethylene to linear alpha olefins (LAOs) for zirconium/aluminum and nickel/zinc catalyst systems. The development of such model helps in the study of the behavior of industrial LAOs reactors as well as in the optimization of their operation. The kinetic model was developed based on a four-step mechanism: site activation, initiation and propagation, chain transfer and site deactivation. A novel stochastic optimization algorithm, Intelligent Firefly Algorithm, was used to obtain the kinetic model parameters that best fit the available experimental data that were obtained from published sources. The values of the kinetic parameters were obtained for the developed kinetic models for two catalyst systems. The performance of the model with the estimated parameters was tested against the experimental data. The proposed kinetic model predicts the product distribution for the zirconium/aluminum catalyst system with suitable accuracy. The model can also predict the product distribution for the nickel/zinc catalyst system with good accuracy for all products. As expected, the accuracy of the model to predict the concentration of the higher carbon products decreases with the carbon number.
\end{abstract}

Keywords Ethylene - Oligomerization - Modeling · Zirconium/aluminum catalyst $\cdot$ Nickel/zinc catalyst

A. A. Mohammed · S.-E. K. Fateen · T. S. Ahmed ( $\varangle)$.

T. M. Moustafa

Chemical Engineering Department, Faculty of Engineering,

Cairo University, Giza 12613, Egypt

e-mail: tamer.s.ahmed@eng1.cu.edu.eg

\begin{tabular}{|c|c|}
\hline Abbrevi & \\
\hline Notation & \\
\hline A & Pre-exponential factor \\
\hline$C_{\mathrm{CAT}}$ & Catalyst concentration, $\mathrm{mol} / \mathrm{l}$ \\
\hline$C_{\mathrm{CAT}}^{k}$ & Active catalyst concentration, mol/1 \\
\hline$C_{\mathrm{CAT}^{k} \cdot \mathrm{M}}$ & $\begin{array}{l}\text { Complex active catalyst/ethylene } \\
\text { concentration, mol/1 }\end{array}$ \\
\hline$C_{\text {decy }}$ & Moles of deactivated catalysts, mol \\
\hline$C_{\mathrm{M}}$ & Concentration of ethylene monomer, mol/l \\
\hline$C_{\mathrm{M}}^{k}$ & Concentration of active ethylene monomer, mol/1 \\
\hline$C_{\mathrm{M}^{k} \cdot \mathrm{TEA}}$ & $\begin{array}{l}\text { Concentration of complex active ethylene } \\
\text { monomer/co-catalyst, mol/l }\end{array}$ \\
\hline$C_{P_{0}}$ & Concentration of active site, $\mathrm{mol} / \mathrm{l}$ \\
\hline$C_{P_{i}}$ & Concentration of living polymers, mol/l \\
\hline$C_{P_{i}^{k}}$ & Concentration of active living polymers, mol/l \\
\hline$C_{P_{i}^{k} \cdot \text { TEA }}$ & $\begin{array}{l}\text { Concentration of complex active living } \\
\text { polymers/co-catalyst, mol/1 }\end{array}$ \\
\hline$C_{\mathrm{TEA}}$ & Co-catalyst concentration, mol/l \\
\hline$C_{\mathrm{TEA}}^{k}$ & Active co-catalyst concentration, $\mathrm{mol} / \mathrm{l}$ \\
\hline$C_{\mathrm{TEA}^{k} \cdot \mathrm{CAT}}$ & $\begin{array}{l}\text { Complex active co-catalyst/catalyst } \\
\text { concentration, mol/1 }\end{array}$ \\
\hline$C_{\mathrm{TEA}_{1}^{k} \cdot \mathrm{CAT}}$ & $\begin{array}{l}\text { Complex active co-catalyst/catalyst } \\
\text { concentration-catalyst, mol/l }\end{array}$ \\
\hline $\mathrm{D}$ & Moles of dead oligomer, mol \\
\hline $\mathrm{E}$ & Activation energy, cal/mol \\
\hline$k_{1}$ & Rate constant of active site \\
\hline$k_{2}$ & Rate constant of chain initiation \\
\hline$k_{3}$ & Rate constant of chain propagation \\
\hline$k_{4}$ & Rate constant of chain transfer \\
\hline$k_{5}$ & Rate constant of deactivation \\
\hline$k_{+1}$ & $\begin{array}{l}\text { Rate constant of attachment of the catalyst in } \\
\text { the site activation }\end{array}$ \\
\hline$k_{-1}$ & $\begin{array}{l}\text { Rate constant of detachment of the catalyst in } \\
\text { the site activation }\end{array}$ \\
\hline
\end{tabular}

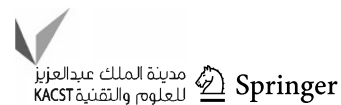


$k_{+2} \quad$ Rate constant of attachment of the monomer in the site activation

$k_{-2} \quad$ Rate constant of detachment of the monomer in the site activation

$k_{+4} \quad$ Rate constant of attachment in the chain propagation reaction

$k_{-4} \quad$ Rate constant of detachment in the chain propagation reaction

$k_{+5} \quad$ Rate constant of attachment in the chain transfer reaction

$k_{-5} \quad$ Rate constant of detachment in the chain transfer reaction

$k_{\mathrm{c}}^{\prime} \quad$ Rate constant of the first reaction of cocatalyst in the site activation

$k_{\mathrm{c}}^{\prime \prime} \quad$ Rate constant of the second reaction of cocatalyst in the site activation

$K_{\mathrm{A}} \quad$ Equilibrium constant of the catalyst in the site activation

$K_{\mathrm{B}} \quad$ Equilibrium constant of the monomer in the site activation

$K_{\mathrm{C}} \quad$ Equilibrium constant of the co-catalyst in the site activation

$K_{\mathrm{D}} \quad$ Equilibrium constant in the chain propagation reaction

$K_{\mathrm{E}} \quad$ Equilibrium constant in the chain transfer reaction

M Ethylene monomer

$\mathrm{M}^{k} \quad$ Active ethylene monomer

$P_{i} \quad$ Living oligomers

$P_{i}^{k} \quad$ Active living oligomers

$P_{0} \quad$ Active site

$\mathrm{R} \quad$ Gas constant, $\mathrm{mol} / \mathrm{cal} \mathrm{K}$

$\mathrm{T} \quad$ Temperature, $\mathrm{K}$

$\mathrm{T}_{\mathrm{r}} \quad$ Reference temperature, $\mathrm{K}$

$v \quad$ Volume, 1

\section{Greek letters}

$\alpha$ Alpha position

\section{Subscripts}

c Calculated mole fractions of product

e Experimental mole fractions of product

CAT Catalyst

$\mathrm{CAT}^{k}$ Active catalyst

TEA Co-catalyst

TEA $^{k}$ Active co-catalyst

\section{Introduction}

Linear alpha olefins (LAOs) are linear hydrocarbons having a double bond between the first and second carbon atoms. Linear $\alpha$-olefins have found wide application in various areas of petrochemical synthesis. They are used for copolymerization with ethylene for the purpose of obtaining low- and high-density linear polyethylene and for the preparation of detergents and synthetic lubricants [12, 14, $41,48,54,61,62]$. They can also be used in the production of surfactants, agents for enhanced oil recovery, corrosion inhibitors, high-performance lubricating oils, linear alkylbenzenes, oxo-synthesis alcohols, $\alpha$-olefin sulfonates, oil additives, and as drilling fluids $[1,3,6,28,35,51,59]$. The worldwide growth rate of LAOs production between 1980 and 1990 amounted to $10-15 \mathrm{wt} \%$ per year. From 1990 to 2000 , the annual increase in LAO production came to $4.5-5 \% \mathrm{wt} \%$. Their average annual demand over the next $10-15$ years is expected to increase by $3.5 \mathrm{wt} \%$. The total amounts of LAOs manufactured worldwide of years 1999, 2003, and 2005 were 2.6, 3.5, and 4.2 million tons, respectively [7].

Ethylene oligomerization is one of the vital industrial processes in which linear alpha olefins can be produced. The products of Ethylene oligomerization can be further separated into different LAOs based the carbon number of the product $[9,38]$. Different industrial processes are used to produce LAOs and extensive research studies are under way on the oligomerization of ethylene in different catalysts and processes conditions. The companies that produce alpha olefins via ethylene oligomerization include Ethyl, Chevron, Shell, Idemitsu, Mitsubishi, IFP-Axens, UOP, and Sabic-Linde [7, 15, 38, 45]. These processes are catalyzed by different Ziegler-Natta catalysts. Investigations of catalytic oligomerization of ethylene have been mainly focused on the complexes of titanium, zirconium, chromium, and nickel for decades. Complexes of titanium and nickel are the most often used catalysts for ethylene oligomerization [47, 49, 58]. Zirconium complexes have also been found to be very active catalyst in this reaction $[5,33$, 34, 42]. The use of other transition metal complexes in ethylene oligomerization is uncommon. $[3,4,17,23,30$, $33,43,44,53,63$ ]

Several authors proposed models to describe the kinetics of the polymerization processes on different catalysts. Zacca and Ray [57] discussed a new model for the polymerization of olefins in a loop reactor. Their reactor was modeled as a two-tubular interconnected reactor. They studied the effects of recycle rate, axial dispersion and heat transfer. Sharma and coworkers [8] developed a mathematical model for the isothermal, slurry polymerization of ethylene using solid Ziegler-Natta catalysts. They discussed the effect of gas liquid mass transfer limitations on the overall rate and polymer properties. Kiparissides [36] produced synthetic polymers via a multitude of reaction mechanisms and processes, including addition and step growth polymerizations. He provided an overview of the different polymerization processes and the mathematical 
modeling approaches and addressed the problems related with the computer-aided design, monitoring, optimization and control of polymerization reactors.

Dube et al. [19] developed a practical methodology for the computer modeling of multi-component chain growth polymerizations, which is applicable to many multi-component systems. Various co-monomer systems were used to illustrate the development of practical semi-batch and continuous reactor operational policies for the manufacture of copolymers with high quality and productivity. Hatzantonis et al. [24] reviewed recent developments in modeling gas phase olefin polymerization fluidized-bed (FBR) reactors in the presence of a multi-site Ziegler-Natta catalyst. In addition, they developed an FBR model to account for the effect of varying of bubble size with the bed height on the reactor dynamics and the molecular properties of the polymer product. They studied the effect of important reactor parameters on the dynamic and steadystate behavior of the FBR. Alhumaizi [2] developed a dynamic mathematical model for the ethylene dimerization reactor to simulate the distribution of butene-1 and other oligomers in the products under different operating conditions. He studied the effects of the recycle flow rate and the cooler heat transfer coefficient for optimum conditions for production of butene-1. Soares [46] reviewed the principal of mathematical modeling techniques for describing the microstructure of polyolefins produced by coordination polymerization. Fernandes and Lona [21, 22] developed a heterogeneous model describing the behavior of the three-phase fluidized-bed reactor in polymer production. The model incorporated the interactions between phases and also predicted the physicochemical properties of the polymer.

Yoon et al. [56] reviewed recent developments in modeling techniques for the calculation of polymer properties and the application of process models to the design of model-based reactor optimizations and controls. Jin et al. [29] developed a mathematical model to simulate the ethylene polymerization in continuous stirred tank reactor. The molecular properties of various polymers were calculated based on the method of moment. Valencia and Soares [52] developed a simulation model for the polymerization of ethylene in a process with $(n)$ reactors working in series, which could predict raw material conversions and product properties. Their model parameters were obtained from laboratory data. Zhang et al. [60] developed a mathematical model to describe the effect of different polymerization conditions on the preparation of ethylene-1-hexene copolymerization with a tandem catalysis system. The general feature of the model simulation agreed well with both their experimentation data and other results reported in the literature. Ghasem and coworkers [26, 27] developed a modified dynamic three-phase structure model that took into account the presence of particles participating in the reaction with emulsion and catalyst phases. The control system was discussed using of neural network controller. In addition, they modified the model to include heat and mass transfer between the bubble and the cloud as well as between the cloud and the emulsion phases. Touloupides et al. [50] developed a comprehensive mathematical model, which was capable of simulating the dynamic operation of an industrial slurry phase cascade loop reactor series under different plant operating conditions. They used multi-site $\mathrm{ZN}$ kinetic and method of moments for calculation of polymer molecular properties.

However, to the best of our knowledge, there has been no published study that proposed kinetic models for the oligomerization of ethylene with zirconium-based catalyst with aluminum-based co-catalyst or with $\operatorname{DPA}(\mathrm{Na}) /$ $\mathrm{NiCl}_{2} \cdot 6 \mathrm{H}_{2} \mathrm{O} / \mathrm{Zn}$ catalyst system. The objective of this work is to develop two kinetic models for the said catalyst systems. The remainder of this paper is divided as follows. "Model formulation" introduces the model formulation. The experimental data are introduced briefly in "Experimental data". "Parameters estimation" describes the methodology of estimating the parameters of the kinetic model using the Intelligent Firefly Algorithm. "Result and discussion" presents the results and discusses its significance. The conclusions of this study are summarized in "Conclusion".

\section{Model formulation}

Many studies focused on the kinetics of olefin polymerization using Ziegler-Natta catalysts. The polymerization reactions occur at several reactive sites on the catalyst. Due to the complexity of the process of polymerization and oligomerization of olefins with Ziegler-Natta catalysts, the mechanism of the reaction is usually divided into a number of reaction steps $[10,11,13,16,25,31,32,37,39,57]$. These steps are:

Site activation

The active site is formed by the reaction between the catalyst with co-catalyst. The co-catalyst acts as an alkylating and reducing agent.

\section{Initiation and propagation}

The active site having a coordination vacancy attracts the electrons in the olefin $\pi$-bond. Coordination is followed by the insertion into the polymer chain $(\mathrm{R})$ and the re-establishment of the coordination vacancy for further monomer insertion. 


\section{Chain transfer}

Several chain transfer mechanisms are applied in Z-N catalyst such as transfer by $\beta$-hydride elimination, transfer to monomer, and transfer to co-catalyst.

Site deactivation

For some polymerizations, the rate of reaction decreases with time due to the catalyst deactivation reaction. The two active sites form the deactivated catalyst, which is inactive for monomer oligomerization. Another deactivation reaction forms a dead polymer chain and a dead catalyst site.

\section{Model mechanism}

The proposed model is limited to the production of $\alpha$ olefins up to $\mathrm{C}_{20}$. The oligomerization reaction can be broken into five parts; catalyst activation, chain initiation, chain propagation, chain transfer and catalyst deactivation.

\section{Model features}

The following points summarize the main features of the model.

1. The concentrations of the catalyst (CAT), ethylene $(\mathrm{M})$, co-catalyst (TEA), and oligomers $\left(P_{i}^{k}\right)$ are divided into active and inactive stages.

2. The catalyst, ethylene, and co-catalyst are involved in the reactions as follows:

active catalyst $\left(\mathrm{CAT}^{k}\right)+$ ethylene $(\mathrm{M}) \stackrel{K_{\mathrm{A}}}{\leftrightarrow} \mathrm{CAT}^{k} \cdot \mathrm{M}$

at equilibrium $k_{+1} * C_{\mathrm{CAT}}^{k} * C_{\mathrm{M}}-k_{-1} C_{\mathrm{CAT}^{k} \cdot \mathrm{M}}=0$

$$
\therefore C_{\mathrm{CAT}^{k} \cdot \mathrm{M}}=K_{\mathrm{A}} C_{\mathrm{CAT}}^{k} * C_{\mathrm{M}}, K_{\mathrm{A}}=\frac{k_{+1}}{k_{-1}}
$$

balance of $C_{\mathrm{CAT}}: C_{\mathrm{CAT}}=C_{\mathrm{CAT}}^{k}+C_{\mathrm{CAT}^{k} \cdot \mathrm{M}}$

$$
C_{\mathrm{CAT}}^{k}=\frac{C_{\mathrm{CAT}}}{K_{\mathrm{A}} C_{\mathrm{M}}+1}
$$

active ethylene $\left(\mathrm{M}^{k}\right)+$ cocatalyst $($ TEA $) \stackrel{K_{\mathrm{B}}}{\leftrightarrow} \mathrm{M}^{k} \cdot$ TEA

at equilibrium $k_{+2} * C_{\mathrm{M}}^{k} * C_{\mathrm{TEA}}-k_{-2} C_{\mathrm{M}^{k} \text {.TEA }}=0$

$$
\begin{array}{r}
\therefore C_{\mathrm{M}^{k} \text { TEA }}=K_{\mathrm{B}} C_{\mathrm{M}}^{k} * C_{\mathrm{TEA}}, K_{\mathrm{B}}=\frac{k_{+2}}{k_{-2}} \\
\text { balance of } C_{\mathrm{M}}: C_{\mathrm{M}}=C_{\mathrm{M}}^{k}+C_{\mathrm{M}^{k} \cdot \mathrm{TEA}} \\
C_{\mathrm{M}}^{k}=\frac{C_{\mathrm{M}}}{K_{\mathrm{B}} C_{\mathrm{TEA}}+1}
\end{array}
$$

$$
\begin{aligned}
& \text { active cocatalyst }\left(\mathrm{TEA}^{k}\right)+\text { catalyst }(\mathrm{CAT}) \stackrel{K_{\mathrm{c}}^{\prime}}{\rightarrow} \mathrm{TEA}^{k} \cdot \mathrm{CAT} \\
& \text { active complex }\left(\mathrm{TEA}^{k} \cdot \mathrm{CAT}\right)+\text { catalyst }(\mathrm{CAT}) \stackrel{K_{\mathrm{c}}^{\prime \prime}}{\rightarrow} \mathrm{TEA}_{1}^{k} \cdot \mathrm{CAT} \\
& C_{\mathrm{TEA}^{k} \cdot \mathrm{CAT}}=k_{\mathrm{c}}^{\prime} C_{\mathrm{TEA}}^{k} C_{\mathrm{CAT}} \\
& C_{\mathrm{TEA}_{1}^{k} \cdot \mathrm{CAT}}=k_{\mathrm{c}}^{\prime \prime} C_{\mathrm{TEA} A^{k} \cdot \mathrm{CAT}} C_{\mathrm{CAT}}=k_{\mathrm{c}}^{\prime \prime} k_{\mathrm{c}}^{\prime} C_{\mathrm{TEA}}^{k} C_{\mathrm{CAT}}^{2} \\
& \text { balance of } C_{\mathrm{TEA}}: C_{\mathrm{TEA}}=C_{\mathrm{TEA}}^{k}+C_{\mathrm{TEA}^{k} \cdot \mathrm{CAT}}+C_{\mathrm{TEA}_{1}^{k} \cdot \mathrm{CAT}} \\
& =C_{\mathrm{TEA}}^{k}+k_{\mathrm{c}}^{\prime} C_{\mathrm{TEA}}^{k} C_{\mathrm{CAT}}+k_{\mathrm{c}}^{\prime \prime} k_{\mathrm{c}}^{\prime} C_{\mathrm{TEA}}^{k} C_{\mathrm{CAT}}^{2} \\
& =C_{\mathrm{TEA}}^{k}\left(1+k_{\mathrm{c}}^{\prime} C_{\mathrm{CAT}}+k_{\mathrm{c}}^{\prime \prime} k_{\mathrm{c}}^{\prime} C_{\mathrm{CAT}}^{2}\right) \\
& \text { Assuming that } k_{\mathrm{c}}^{\prime}=2 K_{\mathrm{c}}, k_{\mathrm{c}}^{\prime \prime}=\frac{k_{\mathrm{c}}^{\prime}}{4} \\
& C_{\mathrm{TEA}}^{k}=\frac{C_{\mathrm{TEA}}}{\left(K_{\mathrm{C}} C_{\mathrm{CAT}}+1\right)^{2}}
\end{aligned}
$$

3. The oligomers of propagation proceed as in the following reaction

$$
\text { TEA }+ \text { active oligomers }\left(P_{i}^{k}\right) \stackrel{K_{\mathrm{D}}}{\leftrightarrow} P_{i}^{k} \cdot \text { TEA }
$$

$$
\text { at equilibrium } k_{+4} * C_{P_{i}}^{k} * C_{\mathrm{TEA}}-k_{-4} C_{P_{i}^{k}} \text { TEA }=0
$$

$$
\therefore C_{P_{i}^{k} \text { TEA }}=K_{\mathrm{D}} C_{P_{i}}^{k} * C_{\mathrm{TEA}}, K_{\mathrm{D}}=\frac{k_{+4}}{k_{-4}}
$$

balance of $C_{P_{i}}: C_{P_{i}}=C_{P_{i}}^{k}+C_{P_{i}^{k} \cdot \mathrm{TEA}} C_{P_{i}^{k}}=\frac{C_{P_{i}}}{K_{\mathrm{D}} C_{\mathrm{TEA}}+1}$

4. The oligomers of chain transfer proceed as in the following reaction:

$$
\text { TEA }+ \text { active oligomers }\left(P_{i}^{k}\right) \stackrel{K_{\mathrm{E}}}{\leftrightarrow} P_{i}^{k} \cdot \text { TEA }
$$

at equilibrium $k_{+5} * C_{P_{i}}^{k} * C_{\mathrm{TEA}}-k_{-5} C_{P_{i}^{k} \text { TEA }}=0$

$$
\therefore C_{P_{i}^{k} \text { TEA }}=K_{\mathrm{E}} C_{P_{i}}^{k} * C_{\mathrm{TEA}}, K_{\mathrm{E}}=\frac{k_{+5}}{k_{-5}}
$$

balance of $C_{P_{i}}: C_{P_{i}}=C_{P_{i}}^{k}+C_{P_{i}^{k} \text { TEA }}$

$$
C_{P_{i}^{k}}=\frac{C_{P_{i}}}{K_{\mathrm{E}} C_{\mathrm{TEA}}+1}
$$

5. The activator affects the rate equations of the chain propagation and chain transfer by rate law of $C_{\mathrm{TEA}}^{a}$ and $C_{\mathrm{TEA}}^{b}$, respectively.

6. Only one single site is involved in the catalytic process.

7. The co-catalyst does not deactivate.

8. The only transfer mechanism included is the transfer to monomer. The transfer reactions are assumed to produce monomer $(\mathrm{M})$ and catalyst $\left(C_{\mathrm{CAT}}\right)$.

The mechanism of the reaction is as follows: 
Site activation

The active catalyst $\left(\mathrm{CAT}^{k}\right)$, active ethylene $\left(\mathrm{M}^{k}\right)$, and active co-catalyst $\left(\mathrm{TEA}^{k}\right)$ react to form active site $\left(P_{0}\right)$. The active center for olefins in Ziegler-Natta catalyst systems is a complex acting as an alkylating and reducing agent.

$$
\begin{gathered}
C_{\mathrm{CAT}}^{k}+C_{\mathrm{M}}^{k}+\frac{1}{2} C_{\mathrm{TEA}}^{k} \stackrel{k_{1}}{\rightarrow} P_{0}+C_{\mathrm{M}}^{k}+\frac{1}{2} C_{\mathrm{TEA}}^{k} \\
r_{1}=k_{1} C_{\mathrm{CAT}}^{k} C_{\mathrm{M}}^{k}\left(C_{\mathrm{TEA}}^{k}\right)^{\frac{1}{2}}
\end{gathered}
$$

Chain initiation

After the catalyst is activated, it is ready to polymerize with monomer. The active site that has a coordination vacancy reacts with an ethylene monomer to form a live oligomer chain of length one $\left(P_{1}^{k}\right)$.

$P_{0}+\mathrm{M} \stackrel{k_{2}}{\rightarrow} P_{1}^{k} \quad r_{2}=k_{2} C_{P_{0}} C_{\mathrm{M}}$

Chain propagation

Coordination is followed by the insertion of a monomer into the chain, which increases the chain length by one monomer unit until chain transfer takes place.

$P_{i}^{k}+\mathrm{M} \stackrel{k_{3}}{\rightarrow} P_{i+1} \quad r_{3}=k_{3} C_{P_{i}^{k}} C_{\mathrm{M}} C_{\text {TEA }}^{a}$

Chain transfer

Chain transfer to monomer may take place if the growing chain abstracts an atom from an unreacted monomer existing in the reaction medium. This leads to the death of the active chain $\left(P_{\mathrm{i}}^{\mathrm{k}}\right)$ to form a dead chain $\left(\mathrm{De}_{i}\right)$ and begins a new one.

$P_{i}^{k}+\mathrm{M} \stackrel{k_{4}}{\rightarrow} \mathrm{De}_{i}+\mathrm{M}+C_{\mathrm{CAT}} \quad r_{4}=k_{4} C_{P_{i}^{k}} C_{\mathrm{M}} C_{\mathrm{TEA}}^{b}$

Site deactivation

Catalyst deactivation happens when active sites form a stable complex that is inactive for monomer oligomerization. Most Ziegler-Natta catalysts deactivate to form deactivation site $\left(C_{\mathrm{d}}\right)$ and/or dead chain $\left(\mathrm{De}_{i}\right)$.

$P_{0} \stackrel{k_{5}}{\longrightarrow} C_{\mathrm{d}} \quad r_{5,0}=k_{5} C_{P_{0}}$

$P_{i} \stackrel{k_{5}}{\rightarrow} C_{\mathrm{d}}+\mathrm{De}_{i} \quad r_{5, i}=k_{5} P_{i}$

Kinetic rate constants are known to be temperature dependent; this dependence is usually described using Arrhenius relationships. The comparative form of the Arrhenius equation was used to estimate kinetic rate constants to improve the convergence in parameter estimation; the rate constants take the form:
$k_{i}=\mathrm{A}_{i} \exp \left(\frac{\mathrm{E}_{i}}{\mathrm{R}}\left(\frac{1}{\mathrm{~T}}-\frac{1}{\mathrm{~T}_{r}}\right)\right)$

\section{Population balance equations in batch reactors}

Population balances are defined for all active species in a batch reactor. Population balance equations describe how the concentrations of living and dead chains of different lengths vary in time during the polymerization in a batch reactor. The material balance for driving population balances in batch reactor for the volume reactor $(v)$ is:

rate of accumulation $=$ rate of generation by chemical reaction

Population balance for active site:

$\frac{1}{v} \frac{\mathrm{d} P_{0}}{\mathrm{~d} t}=\left(r_{1}-r_{2}-r_{5,0}\right)$

For living oligomer chains with $i \geq 2$, the following population balance can be derived:

$\frac{1}{v} \frac{\mathrm{d} P_{i}}{\mathrm{~d} t}=\left(r_{3, i-1}-r_{3, i}-r_{5, i}\right)$

For living oligomer chains with $i=1$, a slightly different equation is applied:

$\frac{1}{v} \frac{\mathrm{d} P_{1}}{\mathrm{~d} t}=\left(r_{2}-r_{3,1}-r_{5,1}\right)$

Similarly, the equations can be derived for dead oligomer formation for $i=2-10$

$\frac{1}{v} \frac{\mathrm{d} D_{i}}{\mathrm{~d} t}=\left(r_{4, i}+r_{5, i}\right)$

The concentration of the catalyst deactivation can be derived as follows:

$\frac{1}{v} \frac{\mathrm{d} C_{\mathrm{decy}}}{\mathrm{d} t}=\sum_{i=1}^{10} r_{5 i}$

\section{Experimental data}

Kinetic modeling in the current study was performed using experimental data obtained from the literature. All experimental data were done in slurry batch reactors. Two sets of experimental data were used in this study to estimate the model parameters for two different catalyst systems. Experimental data (1) are for zirconium-based catalyst and aluminum-based co-catalyst system with molar ratio of $17-45$ between catalyst and co-catalyst, range of temperature $65-95{ }^{\circ} \mathrm{C}$ and pressure 2-4 MPa [40]. Experimental data (2) are for DPA(Na)/ $\mathrm{NiCl}_{2} \cdot 6 \mathrm{H}_{2} \mathrm{O} / \mathrm{Zn}$ catalyst system with ratio of 1.5 between DPA 
(Na) and $\mathrm{NiCl}_{2} \cdot 6 \mathrm{H}_{2} \mathrm{O}$ and a molar ratio of 2-20 between zinc and $\mathrm{NiCl}_{2} \cdot 6 \mathrm{H}_{2} \mathrm{O}$ at $95^{\circ} \mathrm{C}$ and 5.5-6.0 MPa [18].

\section{Parameters estimation}

Regression was performed to obtain the parameters that best fit the model to the experimental data through minimization of the difference between experimental points and model predictions. The objective function for estimation of the model parameters is based on the difference in mole fractions of the products, and it takes the form

$\operatorname{Min}\left(\sum_{i=1}^{n} \sum_{j=1}^{m}\left(y_{e, i, j}-y_{c, i, j}\right)^{2}\right)$

The minimization routine used was a stochastic global optimization routine named the Intelligent Firefly Algorithm (IFA) [20]. Stochastic global optimization algorithms have significant advantages over deterministic optimization methods and thereby deemed more appropriate for our application. IFA is a metaheuristic algorithm, inspired by the flashing behavior of fireflies. The primary purpose for a firefly's flash is to act as a signal system to attract other fireflies, a metaheuristic is a procedure designed to find a good solution to a difficult optimization problem. The Firefly algorithm was developed by Xin-She Yang [55] and it is based on idealized behavior of the flashing characteristics of fireflies. All fireflies are unisex, so that one firefly is attracted to other fireflies regardless of their sex. Attractiveness is proportional to their brightness, thus for any two flashing fireflies, the less bright one will move towards the brighter one. The attractiveness is proportional to the brightness and they both decrease as their distance increases. If no one is brighter than a particular firefly, it will move randomly. The brightness or light intensity of a firefly is determined by the value of the objective function of a given problem.

\section{Results and discussion}

The values of the kinetic parameters for both experimental data used are tabulated and discussed as follows.

Results of experimental data for zirconium/aluminum catalyst system

Values of the proposed model kinetic parameters of experimental data for zirconium/aluminum catalyst system are shown in Table (1).
Table 1 Parameters estimated value for experimental data (1)

\begin{tabular}{|c|c|c|c|}
\hline Parameter & $\begin{array}{l}\text { Estimated } \\
\text { value }\end{array}$ & Unit & Expression \\
\hline A1 & $4.525 \times 105$ & $1 /(\mathrm{mol} \mathrm{s})$ & A factor of activation \\
\hline E1 & $3.985 \times 103$ & $\mathrm{cal} / \mathrm{mol}$ & $\begin{array}{l}\text { Activation energy of activation } \\
\text { and deactivation }\end{array}$ \\
\hline $\mathrm{A} 2$ & $5.101 \times 108$ & $1 /(\mathrm{mol} \mathrm{s})$ & A factor of initiation \\
\hline E2 & $5.267 \times 104$ & $\mathrm{cal} / \mathrm{mol}$ & Activation energy of initiation \\
\hline A3 & $4.949 \times 108$ & $1 /(\mathrm{mol} \mathrm{s})$ & A factor of propagation \\
\hline E3 & $1.514 \times 104$ & $\mathrm{cal} / \mathrm{mol}$ & $\begin{array}{l}\text { Activation energy of } \\
\text { propagation }\end{array}$ \\
\hline A4 & $4.650 \times 105$ & $1 /(\mathrm{mol} \mathrm{s})$ & A factor of Chain transfer \\
\hline E4 & $1.433 \times 104$ & $\mathrm{cal} / \mathrm{mol}$ & $\begin{array}{l}\text { Activation energy of Chain } \\
\text { transfer }\end{array}$ \\
\hline A5 & 1.255 & $1 / \mathrm{s}$ & A factor of deactivation \\
\hline$K_{\mathrm{A}}$ & $4.812 \times 102$ & $1 / \mathrm{mol}$ & $\begin{array}{l}\text { Equilibrium constant of the } \\
\text { catalyst in the site activation }\end{array}$ \\
\hline$K_{\mathrm{B}}$ & $2.771 \times 102$ & $1 / \mathrm{mol}$ & $\begin{array}{l}\text { Equilibrium constant of the } \\
\text { monomer in the site activation }\end{array}$ \\
\hline$K_{\mathrm{C}}$ & $6.906 \times 103$ & $1 / \mathrm{mol}$ & $\begin{array}{l}\text { Equilibrium constant of the co- } \\
\text { catalyst in the site activation }\end{array}$ \\
\hline$K_{\mathrm{D}}$ & $4.083 \times 104$ & $1 / \mathrm{mol}$ & $\begin{array}{l}\text { Equilibrium constant in the } \\
\text { chain propagation reaction }\end{array}$ \\
\hline$K_{\mathrm{E}}$ & $5.955 \times 101$ & $1 / \mathrm{mol}$ & $\begin{array}{l}\text { Equilibrium constant in the } \\
\text { chain transfer reaction }\end{array}$ \\
\hline$a$ & 1.116 & & \\
\hline$b$ & 0.954 & & \\
\hline
\end{tabular}

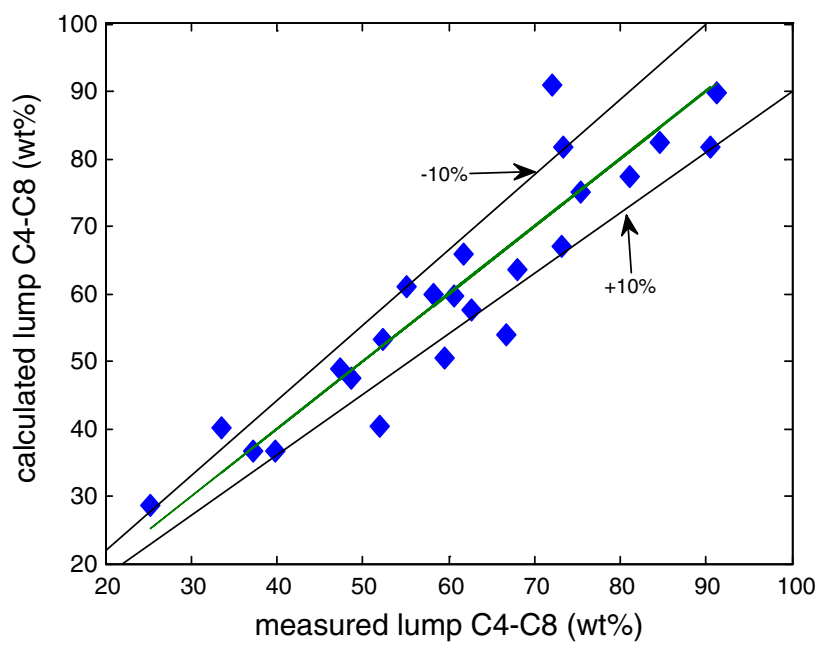

Fig. 1 Comparison calculated and measured data of lumped $\mathrm{C}_{4}, \mathrm{C}_{6}$ and $\mathrm{C}_{8}$ product

Figure (1) shows the parity plot for lumped butane, hexane and octane using the estimated parameters. Each point represents one experimental run. Almost $80 \%$ of the points are predicted with $<10 \%$ error lines. Figure (2) shows the experimental and calculated points for $\mathrm{C}_{10+}$. It is clear that many runs are predicted outside the $20 \%$ error boundary lines. 


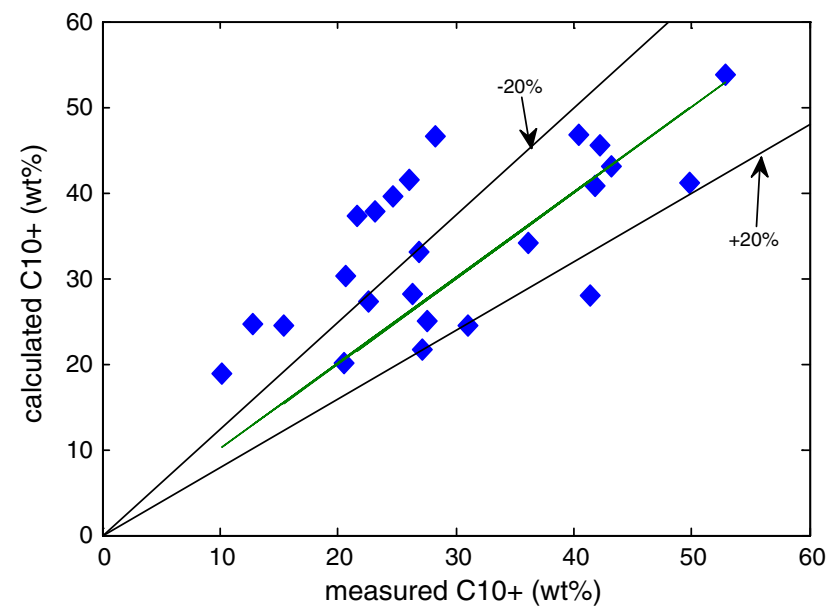

Fig. 2 Comparison calculated and measured data of $\mathrm{C}_{10+}$ product

Table 2 Kinetic parameters of experimental data (2)

\begin{tabular}{|c|c|c|c|}
\hline Parameter & $\begin{array}{l}\text { Estimated } \\
\text { value }\end{array}$ & Unit & Expression \\
\hline A1 & $4.447 \times 106$ & $1 /(\mathrm{mol} \mathrm{s})$ & A factor of activation \\
\hline E1 & $1.455 \times 103$ & $\mathrm{cal} / \mathrm{mol}$ & $\begin{array}{l}\text { Activation energy of activation } \\
\text { and deactivation }\end{array}$ \\
\hline A2 & $6.842 \times 108$ & $1 /(\mathrm{mol} \mathrm{s})$ & A factor of initiation \\
\hline E2 & $4.757 \times 104$ & $\mathrm{cal} / \mathrm{mol}$ & Activation energy of initiation \\
\hline A3 & $5.928 \times 105$ & $1 /(\mathrm{mol} \mathrm{s})$ & A factor of propagation \\
\hline E3 & $1.237 \times 104$ & $\mathrm{cal} / \mathrm{mol}$ & $\begin{array}{l}\text { Activation energy of } \\
\text { propagation }\end{array}$ \\
\hline A4 & $2.634 \times 105$ & $1 /(\mathrm{mol} \mathrm{s})$ & A factor of Chain transfer \\
\hline E4 & $1.137 \times 104$ & $\mathrm{cal} / \mathrm{mol}$ & $\begin{array}{l}\text { Activation energy of Chain } \\
\text { transfer }\end{array}$ \\
\hline A5 & 0.973 & $1 / \mathrm{s}$ & A factor of deactivation \\
\hline$K_{\mathrm{A}}$ & $8.546 \times 104$ & $1 / \mathrm{mol}$ & $\begin{array}{l}\text { Equilibrium constant of the } \\
\text { catalyst in the site activation }\end{array}$ \\
\hline$K_{\mathrm{B}}$ & $1.464 \times 104$ & $1 / \mathrm{mol}$ & $\begin{array}{l}\text { Equilibrium constant of the } \\
\text { monomer in the site activation }\end{array}$ \\
\hline$K_{\mathrm{C}}$ & $9.750 \times 103$ & $1 / \mathrm{mol}$ & $\begin{array}{l}\text { Equilibrium constant of the co- } \\
\text { catalyst in the site activation }\end{array}$ \\
\hline$K_{\mathrm{D}}$ & $7.946 \times 104$ & $1 / \mathrm{mol}$ & $\begin{array}{l}\text { Equilibrium constant in the } \\
\text { chain propagation reaction }\end{array}$ \\
\hline$K_{\mathrm{E}}$ & $9.604 \times 103$ & $1 / \mathrm{mol}$ & $\begin{array}{l}\text { Equilibrium constant in the } \\
\text { chain transfer reaction }\end{array}$ \\
\hline$a$ & 0.845 & & \\
\hline$b$ & 0.919 & & \\
\hline
\end{tabular}

Results for experimental data for nickel/zinc catalyst system

Values of the proposed models' kinetic parameters for experimental data for nickel/zinc catalyst system are shown in Table (2).

Figure (3) shows the parity plot of lumped butane, hexane and octane using the estimated parameters. All the

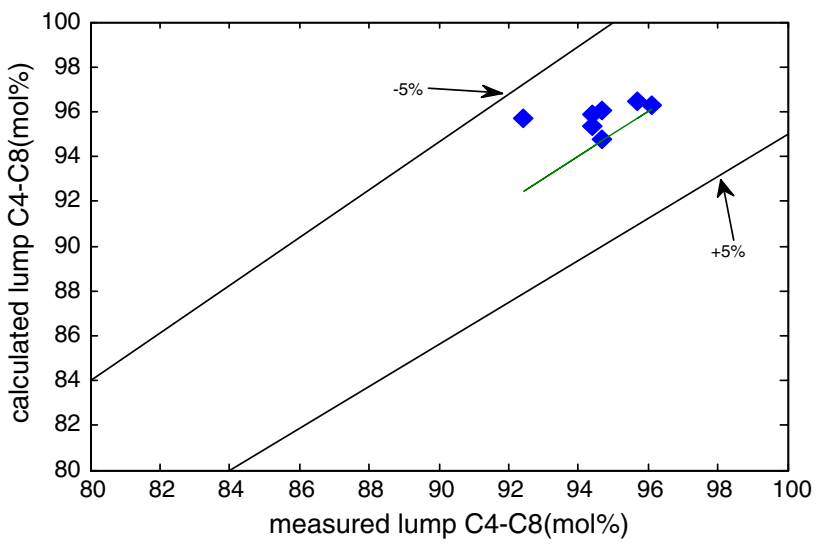

Fig. 3 Comparison calculated and measured data of lumped $\mathrm{C}_{4}, \mathrm{C}_{6}$ and $\mathrm{C}_{8}$ product

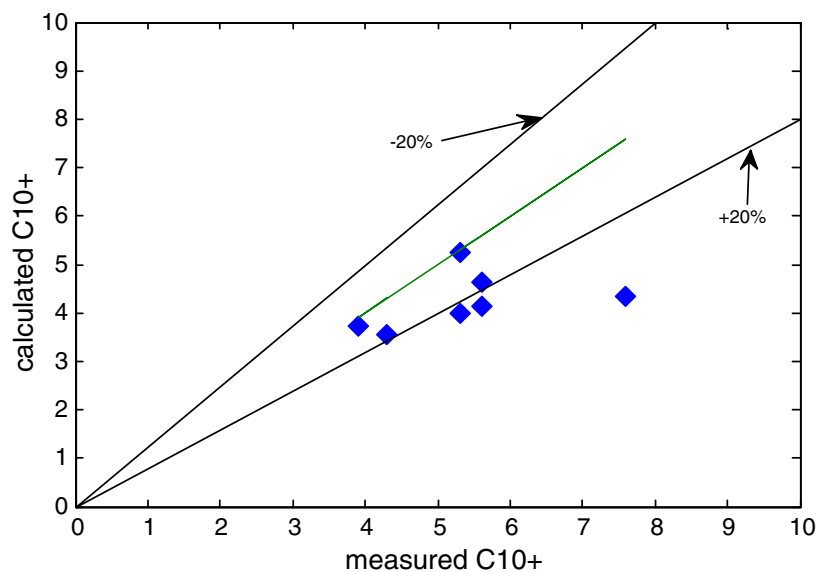

Fig. 4 Comparison calculated and measured data of $\mathrm{C}_{10+}$ product

points lay between the $5 \%$ error lines for all three products. Figure (4) shows the experimental and calculated points for $\mathrm{C}_{10+}$ production. Some of the runs are predicted outside the $20 \%$ error boundary lines.

The results show that the proposed model predicts both experimental data for zirconium/aluminum and nickel/zinc catalyst systems in a different way. The prediction of the model is better for lump $\mathrm{C}_{4}-\mathrm{C}_{8}$ compared to $\mathrm{C}_{10+}$. For lump $\mathrm{C}_{4}-\mathrm{C}_{8}$, the model predictions for the zirconium/aluminum catalyst system lie mostly between the $10 \%$ confidence limits. On the other hand, for the nickel/zinc catalyst system, the model predictions for lump $\mathrm{C}_{4}-\mathrm{C}_{8}$ lie between the $5 \%$ confidence limits. As for the $\mathrm{C}_{10+}$, the prediction of the model is lower for both systems. In both catalyst systems, most of the points lie between the $20 \%$ confidence limits.

The results show that the proposed model fits the experimental data for nickel/zinc catalyst system with higher accuracy as compared to the experimental data for zirconium/aluminum catalyst system. This may be 
attributed to that for the zirconium/aluminum catalyst system, the experimental data for the reaction are available over a wide temperature range, while for the nickel/zinc catalyst system, the experimental data are only available at a constant temperature.

Finally, the model prediction is better for low carbon atoms. As the number of carbon atoms increases, the concentration of the polymer decreases and the model fails to predict the product concentration. The formation of higher carbon number polymer is a complex process that may not be well represented by this simple model. Relaxing some of the model assumptions may positively affect the results of its prediction.

\section{Conclusions}

A kinetic model of the oligomerization of ethylene was proposed in this study. Two sets of experimental data were used for the estimation of the model parameters. The performance of the model with estimated parameters has been tested against the experimental data. The proposed model predicts the product distribution for experimental data for zirconium/aluminum catalyst system with a suitable accuracy. The model predictions of the concentration for the components of $\mathrm{C}_{4}$ up to $\mathrm{C}_{8}$ fit within the $10 \%$ confidence limits, while the absolute errors for $\mathrm{C}_{10+}$ were higher between the $20 \%$ confidence limits. Similarly, the model could predict the experimental data for nickel/zinc catalyst system well. The prediction accuracy was better in comparison to the prediction of the zirconium/aluminum catalyst kinetic model. This may be attributed to that for the zirconium/aluminum catalyst system, the experimental data for the reaction are available over a wide temperature range, while for the nickel/zinc catalyst system, the experimental data are only available at a constant temperature. Finally, the model prediction is better for low carbon atoms. Relaxing some of the model assumptions may positively affect the results of its prediction. In all cases, the importance of the model lies in its ability to predict the concentration of the low carbon number oligomers.

Open Access This article is distributed under the terms of the Creative Commons Attribution License which permits any use, distribution, and reproduction in any medium, provided the original author(s) and the source are credited.

\section{References}

1. Agapie T (2011) Selective ethylene oligomerization: recent advances in chromium catalysis and mechanistic investigations. Coord Chem Rev 255:861-880
2. Alhumaizi KI (2000) Stability Analysis of the Ethylene Dimerization Reactor for the Selective Production of Butene-1. Chem Eng Res Des 78:492-497

3. Aliyev V, Mosa F, Al-Hazmi M (2010) Catalyst composition for oligomerization of ethylene oligomerization process and method for its preparation. US 2010/0292423 A1 1-5

4. Al-Jarallah AM, Anabtawi JA, Siddiqui MAB, Aitani AM, AlSa'doun AW (1992) Ethylene dimerization and oligomerization to butene- 1 and linear $\alpha$-olefins: a review of catalytic systems and processes. Catal Today 14:1-121

5. Attridger J, Jackson R, Maddock J, Thompson T (1973) Ethylene oligomerisation with zirconium arylalkyls and alkenyls. J Chem Soc Chem Commun 1973:132-133

6. Bahuleyan BK, Ahn IY, Appukuttan V, Lee SH, Ha C-S, Kim I (2010) Ethylene oligomerization by tridentate cobalt complexes bearing pendant donor modified $\alpha$-diimine ligands. Macromol Res 18:701-704

7. Belov GP, Matkovsky PE (2010) Processes for the production of higher linear $\alpha$-olefins. Pet Chem 50:283-289

8. Bhagwat MS, Bhagwat SS, Sharma MM (1994) Mathematical modeling of the slurry polymerization of ethylene: gas-liquid mass transfer limitations. Ind Eng Chem Res 33:2322-2330

9. Bianchini C, Giambastiani G, Rios IG, Mantovani G, Meli A, Segarra AM (2006) Ethylene oligomerization, homopolymerization and copolymerization by iron and cobalt catalysts with 2,6(bis-organylimino)pyridyl ligands. Coord Chem Rev 250:1391-1418

10. Bohm LL (1978) Ethylene polymerization process with a highly active Ziegler-Natta catalyst: 1. Kinet Polym (Guildf) 19:553-561

11. Bohm LL (1978) Reaction model for Ziegler-Natta polymerization processes. Polym (Guildf) 19:545-552

12. Cai T (1999) Studies of a new alkene oligomerization catalyst derived from nickel sulfate. Catal Today 51:153-160

13. De Carvalho AB, De Gloor PE, Hamielec AE (1989) A kinetic mathematical model for heterogeneous Ziegler-Natta copolymerization. Polym (Guildf) 30:280-296

14. Chandran D, Kwak CH, Oh JM, Ahn IY, Ha C-S, Kim I (2008) Ethylene oligomerizations by sterically modulated salicylaldimine cobalt(II) complexes combined with various alkyl aluminum cocatalysts. Catal Lett 125:27-34

15. Choo H, Kevan L (2001) Catalytic study of ethylene dimerization on $\mathrm{Ni}$ (II) -exchanged clinoptilolite. J Phys Chem B 105:6353-6360

16. Deffieux A, Fontanille M, Ribeiro MR, Portela MF (1996) Kinetic investigation of parameters governing the high-temperature polymerization of ethylene initiated by supported $\mathrm{VCl} 3$ catalytic systems. Eur Polym J 32:811-819

17. Dixon JT, Green MJ, Hess FM, Morgan DH (2004) Advances in selective ethylene trimerisation-a critical overview. J Organomet Chem 689:3641-3668

18. Dong-bing Liu DL (1998) Catalytic oligomerization of ethylene to lower $\alpha$-olefins by the catalyst system $\mathrm{DPA}(\mathrm{Na}) / \mathrm{NiC} 12.6 \mathrm{H} 2 \mathrm{O} /$ Zn. Appl Catal A Gen 166:L255-L258

19. Dube MA, Soares JBP, Penlidis A, Hamielec AE (1997) Mathematical modeling of multicomponent chain-growth polymerizations in batch, semibatch, and continuous reactors: a review. Ind Eng Chem Res 36:966-1015

20. Fateen S-EK, Bonilla-Petriciolet A (2013) Intelligent firefly algorithm for global optimization. In: X. Yang (ed) Springer, Germany

21. Fernandes FAN, Lona LMF (2002) Heterogeneous modeling of fluidized bed polymerization reactors. Influence of mass diffusion into the polymer particle. Chem Eng Sci 26:841-848

22. Fernandes FAN, Lona LMF (2001) Heterogeneous modeling for fluidized-bed polymerization reactor. Chem Eng Sci 56:963-969 
23. Hang W, Weidong Y, Tao J, Binbin L, Wenqing X, Jianjiang M, Youliang H (2002) Ethylene oligomerization by novel iron (II) diimine complexes/MAO. Chin Sci Bull 47:1616-1618

24. Hatzantonis H, Yiannoulakis H, Yiagopoulos A, Kiparissides C (2000) Recent developments in modeling gas-phase catalyzed olefin polymerization fluidized-bed reactors: the effect of bubble size variation on the reactor's performance. Chem Eng Sci 55:3237-3259

25. Huang J, Rempel GL (1995) Ziegler-Natta catalysts for olefin polymerization: mechanistic insights from metallocene systems. Prog Polym Sci 20:459-526

26. Ibrehem AS, Hussain MA, Ghasem NM (2009) Modified mathematical model for gas phase olefin polymerization in fluidizedbed catalytic reactor. Chem Eng J 149:353-362

27. Ibrehem PS, Hussain MA, Ghasem NM (2008) Mathematical model and advanced control for gas-phase olefin polymerization in fluidized-bed catalytic reactors. Chin J Chem Eng 16:84-89

28. Jiang T, Chen H, Ning Y, Chen W (2006) Preparation of 1-octene by ethylene tetramerization with high selectivity. Chin Sci Bull 51:521-523

29. Jin X, Hu P, Dong S, Yuan P (2004) steady-state modeling of ethylene polymerization. 5Ih World Congr. Intell Control Autom China pp 3493-3497

30. Jones D, Cavell K, Keim W (1999) Zirconium complexes as catalysts for the oligomerisation of ethylene: the role of chelate ligands and the Lewis acid cocatalyst in the generation of the active species. J Mol Catal A Chem 138:37-52

31. Asua José M (2007) Polymer reaction engineering. Blackwell Publishing Ltd, UK

32. Kazuo Soga TS (1997) Ziegler-Natta catalysts polymerizations. Prog Polym Sci 22:1503-1546

33. Khanmetov AA, Azizov AG, Ibragimova MD, Kuliev BV, Alieva RV, Kalbalieva ES, Bagirova SR, Mamedova RZ (2007) The multiple-site nature of ethylene polymerization catalysts based on zirconyl carboxylates. Pet Chem 47:176-183

34. Khanmetov AA, Azizov AG, Piraliev AG (2006) Ethylene oligomerization in the presence of catalyst systems based on mixedligand $\beta$-diketonatozirconium chlorides. Pet Chem 46:338-342

35. Kim I, Kwak CH, Kim JS, Ha C-S (2005) Ethylene oligomerizations to low-carbon linear $\alpha$-olefins by structure modulated phenoxy-imine nickel(II) complexes combined with aluminum sesquichloride. Appl Catal A Gen 287:98-107

36. Kiparissides CA (1996) Polymerization reactor modeling: a review of recent developments and future directions. Chem Eng Sci 51:1637-1659

37. Kissin V, Mink I, Company MC, October R, Manuscript R, January R (1993) Ethylene oligomerization and chain growth mechanisms with Ziegler-Natta catalysts. Macromolecules 26:2151-2158

38. Fan-Hua Kong, Ming-He Xie (1999) Catalysts for 1-hexene Synthesis from Ethylene Oligomerization. J Nat Gas Chem 8:256-263

39. Meyer T, Keurentjes J (2005) Handbook of polymer reaction engineering, 1st edn. Wiley-VCH

40. Moustafa TM (2005) Unpublished data

41. Nelkenbaum E, Kapon M, Eisen MS (2005) Synthesis and molecular structures of neutral nickel complexes. Catalytic activity of the oligomerization of ethylene, and the dimerization of propylene. Organometallics 24:2645-2659

42. Oouchi K, Mitani M, Hayakawa M, Yamada T (1996) Ethylene oligomerization catalyzed with dichlorobis- (P-diketonato) zirconium/organoaluminium chloride systems. Macromol Chem Phys 1551:1545-1551

43. Shiraki Y, Nakamoto Y, Souma Y (2002) ZrCl 4 -TEA-EASC three-component catalyst for the oligomerization of ethylene: the role of organoaluminum co-catalysts and additives. J Mol Catal A Chem 187:283-294
44. Siedle AR, Lamanna WM, Newmark RA, Schroepfer JN (1998) Mechanism of olefin polymerization by a soluble zirconium. J Mol Catal A Chem 128:257-271

45. Skupiňsk J (1991) Oligomerization of $\alpha$-olefins to higher oligomers. Chem Rev 91:613-648

46. Soares BP (2001) Mathematical modelling of the microstructure of polyoleÿns made by coordination polymerization: a review. Chem Eng Sci 56:4131-4153

47. de Souza RF, Bernardo-Gusmão K, Cunha GA, Loup C, Leca F, Réau R (2004) Ethylene dimerization into 1-butene using 2-pyridylphosphole nickel catalysts. J Catal 226:235-239

48. Su B, Feng G (2010) Influence of the metal centers of 2,6bis(imino)pyridyl transition metal complexes on ethylene polymerization/oligomerization catalytic activities. Polym Int 59:1058-1063

49. Tembe GL, Ravindranathan M (1991) Oligomerization of ethylene to linear a-olefins by a titanium aryl oxide-alkylaluminum catalyst. Ind Eng Chem Res 30:2247-2252

50. Touloupides V, Kanellopoulos V, Pladis P, Kiparissides C, Mignon D, Van-Grambezen P (2010) Modeling and simulation of an industrial slurry-phase catalytic olefin polymerization reactor series. Chem Eng Sci 65:3208-3222

51. Turner AH (1983) Purity aspects of higher alpha olefins. J Am Oil Chem Soc 60:623-627

52. Valencia FP, Soares JBP (2007) Steady state simulation of ethylene polymerization using multiple-site coordination catalysts. Macromol Symp 259:110-115

53. Wang M, Li R, Qian M, Yu X, He R (2000) The effect of cocatalysts on the oligomerization and cyclization of ethylene catalyzed by zirconocene complexes. J Catal A Chem 160:337-341

54. Yang $\mathrm{P}$, Yang Y, Zhang C, Yang X-J, Hu H-M, Gao Y, Wu B (2009) Synthesis, structure, and catalytic ethylene oligomerization of nickel(II) and cobalt(II) complexes with symmetrical and unsymmetrical 2,9-diaryl-1,10-phenanthroline ligands. Inorganica Chim Acta 362:89-96

55. Yang XS (2008) Firefly algorithm. Nature-inspired metaheuristic algorithms. Luniver Press, Frome, pp 79-90

56. Yoon WJ, Kim YS, Kim IS, Choi KY (2004) Recent advances in polymer reaction engineering: modeling and control of polymer properties. Korean J Chem Eng 21:147-167

57. Zacca JJ, Ray H (1993) Modelling of the liquid phase polymerization of olefins in loop reactors. Chem Eng Sci 48:3743-3765

58. Zaidman AV, Kayumov RR, Belov GP, Pervova IG, Lipunov IN, Kharlampidi KE (2010) Ethylene oligomerization in the presence of catalytic systems based on nickel(II) formazanates. Pet Chem $50: 450-454$

59. Zhang B, Wang Y, Wang G, Cao J, Sun S, Xing L, Sun Y, Han Y (2007) Oligomerization and polymerization of ethylene initiated by a novel Ni (II) -based acetyliminopyridine complexes as single-site catalysts. J Nat Gas Chem 16:64-69

60. Zhang J, Fan H, Li B-G, Zhu S (2008) Modeling and kinetics of tandem polymerization of ethylene catalyzed by bis(2-dodecylsulfanyl-ethyl)amine- and. Chem Eng Sci 63:2057-2065

61. Zhang Z, Chen S, Zhang X, Li H, Ke Y, Lu Y, Hu Y (2005) A series of novel 2,6-bis(imino)pyridyl iron catalysts: synthesis, characterization and ethylene oligomerization. J Mol Catal A Chem 230:1-8

62. Zhang Z, Zou J, Cui N, Ke Y, Hu Y (2004) Ethylene oligomerization catalyzed by a novel iron complex containing fluoro and methyl substituents. J Mol Catal A Chem 219:249-254

63. Zhukov VI, Val'kovich GV, Skorik IN, Petrov YM, Belov GP (2007) Ethylene oligomerization in the presence of $\mathrm{ZrO}(\mathrm{O}$ $\mathrm{COR}) 2-\mathrm{Al}(\mathrm{C} 2 \mathrm{H} 5) 2 \mathrm{Cl}-\mathrm{Modifier}$ catalytic system. Pet Chem $47: 49-54$ 